\title{
Life cycle assessment study of a field emission display television device
}

\author{
Roland Hischier
}

Received: 2 April 2013 / Accepted: 24 September 2014 / Published online: 8 October 2014

(C) Springer-Verlag Berlin Heidelberg 2014

\begin{abstract}
Purpose An life cycle assessment (LCA) study of a field emission display (FED) television device was established. The first objective of this study was to get an up-to-date and comprehensive picture by applying the latest developments in the area of LCA, especially concerning the use of nanoparticles. In its second part, the study shows a comparison with today's display technologies (i.e. CRT, LCD, plasma) and the timely development of the assessment of a FED television device.

Methods This LCA study covers the complete life cycle of a FED television device in accordance with the ISO 14040 standard, from the extraction of raw materials until the final end-of-life treatment in a European WEEE recycling system. Two different functional units were applied in this study: For the in-depth analysis of the FED television device, an entire device along its complete life cycle was considered as functional unit-for the subsequent comparison with today's display technologies, "one square-inch of display during $1 \mathrm{~h}$ of active use" was used as an appropriate functional unit. Main data source for the FED device was patent information; ecoinvent was used as default background database.

Results and discussion The in-depth analysis of this FED television device shows a clear dominance of the production phase (independently of the impact category). Within the production of such a device, the electronics part (i.e. the
\end{abstract}

Responsible editor: Berlan Rodriguez Perez

Electronic supplementary material The online version of this article (doi:10.1007/s11367-014-0806-2) contains supplementary material, which is available to authorized users.

R. Hischier $(\bowtie)$

Environmental Risk Assessment \& Management Group, Swiss Federal Laboratories for Materials Science and Technology (Empa), Technology \& Society Lab (TSL), Lerchenfeldstrasse 5, 9014 St. Gallen, Switzerland

e-mail: roland.hischier@empa.ch printed wiring boards) shows the highest contribution — while, even when focussing on the glass and its various coating layers only, the carbon nanotubes (CNTs) production has a very minor influence. The releases of CNTs during the Endof-Life treatment do not contribute in a relevant manner to the overall impact neither-even when focussing on the "ecotoxicity potential" by using conservative CFs reported for this type of releases. Last but not least, the comparison with the existing television display technologies shows that an FED device has an environmental advantage over all three other technologies using the above stated functional unit of "one square-inch of display during $1 \mathrm{~h}$ of active use".

Conclusions Traditional impact categories as well as the ecotoxicity factor results in clear environmental advantages for an FED television device when comparing it to the three display technologies used today. Concerning the general issue of evaluating applications of manufactured nanomaterials in LCA studies, this case study shows the high relevance of an adequate integration of nanoparticle releases into LCA studies in order to achieve an actually comprehensive evaluation.

Keywords Carbon nanotubes $\cdot \mathrm{CNT} \cdot \mathrm{FED} \cdot$ Field emission display $\cdot$ Life cycle assessment $\cdot$ LCA $\cdot$ Manufactured nanomaterial $\cdot \mathrm{MNM}$

\section{Introduction}

Displays are an important interface in machine-based communication among human beings — or, as summed up, e.g. in Gurski and Quach (2005), "a picture is worth a thousand words". In 2009, more than $92 \%$ of all households in Switzerland had at least one television device and more than $80 \%$ had at least one desktop computer (having an additional screen). In 2011, each person in Switzerland spent on average 
from $2 \mathrm{~h}$ and $17 \mathrm{~min}$ (German part) up to $2 \mathrm{~h}$ and $52 \mathrm{~min}$ (Italian part of Switzerland) in front of a television (BfS 2013).

The area of display technologies (both, for television devices as well as for computer screens) has been dominated by the cathode ray tube (CRT) technology since the 1920s — with many different flat panel display (FPD) technologies coming up since the late twentieth century, ranging between various self-emissive and non-emissive technologies (Gurski and Quach 2005; Leung 2008). Concerning television devices, a consumer today looks for "improved features in thinness, brightness, contrast ratio, viewing angle, longevity, size, and reduced weight \& power consumption" (ObservatoryNANO 2011). According to this latter report, a variety of different technologies have emerged in television devices for this, but not any one of them fulfils all requirements; each one has not only advantages, but also constraints, as shown in Table 1 for the most popular of these different FPD technologies.

This article focusses in the following on the last FPD technology mentioned in Table 1, i.e. field emission display (FED) technology, and its application in the area of television devices.

\subsection{Field emission display technology}

According to Chalamala et al. (1998), the FED technology can be best compared to the CRT technology. Both of them are based on the principle of a cathode that (in a vacuum) launches electrons towards a glass plate coated with phosphorous. But whereas in the CRT technology just one such cathode is used, the FED technology uses one individual cathode for each single pixel. In this way, this new technology allows the construction of devices with very promising features like, e.g. a thin, self-emissive screen, a distortion free image, or a wide viewing angle (Zeng et al. 2006). Within the FED technology, two main development streams can be distinguished: SED and NED. SED stands for "surface-conduction electron-emitter display" technology and represents the FED technology developed by Canon and Toshiba (Fink et al. 2007). NED is the "nano-emissive display" technology developed by Motorola (Coll et al. 2006). While the first one uses lateral field emitters - the latter one represents a cost-efficient way of producing large display sizes (Dean 2010).

A great challenge in the development of the FED technology is the issue of micro fabrication of the cathodes in order to have one cathode per pixel. For this, carbon nanotubes (CNT), a manufactured nanomaterial (MNM), appear to be a valuable alternative to traditional microtip structures (Zheng et al. 2009). Then according to Dean (2007), CNTs offer the best behaviour (both in production and in use) concerning the required characteristics of a display technology (i.e. stable structures, no support for creation of harmful oxides or sulphides; and the ability to self-assemble in the presence of a respective catalyst). These various technical features of CNTs allow a screen based on the FED technology in the end to be as bright as a CRT screen, by being as thin as today's LCD screens (Chalamala et al. 1998; Dean 2010; Zeng et al. 2006; or Verma 2010).

\subsection{The environmental sustainability of display technologies}

Although with life cycle assessment (LCA) a comprehensive framework is available for an evaluation of the ecological side of sustainability and specific guidelines for the use of this framework in the area of electronics have been published by the related industry recently (ETSI 2011), it has thus far been possible to find only few such studies of flat screen technologies, including the FED technology. A very first LCA study of a television device was published more than 15 years ago (Thomas et al. 1988); but since then, only a handful of additional studies have been published (Aoe 2003; IPTS 2003; Hischier and Baudin 2010; Feng and Ma 2009) dealing with traditional television devices, i.e. devices based on CRT, LCD, or PDP technology. According to Andrae and Andersen (2010) - analysing the consistency of different studies dealing with the same type of consumer electronic device-the results of television LCA studies are more consistent than those of other types of devices (e.g. laptop computers). Concerning screen and/or television devices based on the FED technology, LCA studies are even scarcer. A first such study, but on a qualitative level only, was published in 2004 (Steinfeldt et al. 2004), followed by two quantitative studies according to the ISO 14040 standard (ISO 2006) in 2007 and 2008. The first one (Steinfeldt 2007) dealt with an FED device estimated via data for the LCD technology, while the 2008 study (Bauer et al. 2008) focussed on a "hypothetical" FED computer screen as case study. However, both studies were established before the tool LCA had been properly adapted for a use in the area of nanotechnology; then as shown in several recent review articles (e.g. Hischier and Walser 2012) hardly any LCA studies were published in the area of nanotechnology up to 2007. The two abovementioned FED studies lack therefore adequate, comprehensive background data of the production of CNTs as well as characterisation factors (CFs) for the subsequent environmental impact assessment of possible releases of CNTs along the life cycle. While writing this publication, a screening-level LCA study of an FED device has been published (Upadhyayula et al. 2012, 2014). According to this study, using the US-LCIA method TRACI, the main impact results from the production (being responsible for two third and more of the impact), while the subsequent use over $10,000 \mathrm{~h}$ (according to the authors, the viewing life-span of such a device) and the end-of-life treatment are of minor relevance only. 
Table 1 Advantages and disadvantages of most popular Flat Panel Display Technologies (information based on Gurski and Quach 2005; ObservatoryNANO 2011; Salmon 2012)

\begin{tabular}{|c|c|c|}
\hline Technology & Advantages & Disadvantages \\
\hline \multirow[t]{2}{*}{ LCD } & - More energy efficient (than CRT) & - Colours and contrast changes with viewing angle \\
\hline & - Safer disposal option & - Motion rendition may be inadequate \\
\hline \multirow[t]{2}{*}{ PDP } & - Large viewing angles, high image quality & - Susceptible to burn-in effects \\
\hline & - Size does not harm the image quality & - Rather high energy consumption \\
\hline \multirow[t]{3}{*}{ OLED } & • Emissive display (no backlight needed) & • Relatively short lifespan \\
\hline & \multirow{2}{*}{$\begin{array}{l}\text { - Surpasses LCD for viewing angle, brightness, contrast, and power } \\
\text { efficiency }\end{array}$} & - Color balance issues (blue color) \\
\hline & & • Poor sunlight readability \\
\hline FED & $\begin{array}{l}\text { - High contrast } \\
\text { - Low energy consumption }\end{array}$ & $\begin{array}{l}\text { - Requires high vacuum level to operate (challenging } \\
\text { production) }\end{array}$ \\
\hline
\end{tabular}

$L C D$ liquid crystal display, $P D P$ plasma display panel, $O L E D$ organic light emitting diode, $F E D$ field emission display

\subsection{Latest developments in the area of LCA}

As shown by various recent review studies (e.g. Hischier and Walser 2012), the LCA method has been adapted, expanded for a use in the area of nanotechnology in the last few years only. Results of this development are, e.g. the publication of life cycle inventory data about the production of various MNM, among them CNT (Healy et al. 2008; Isaacs et al. 2010), the publication of a framework for a systematic modelling of releases of nanoparticles along the complete life cycle (Hischier 2014), as well as first estimations of CFs in the area of ecotoxicity for the assessment of releases of nanoparticles (Eckelman et al. 2012; Salieri 2013). All this allows today a much more comprehensive LCA analysis of products and/or services using MNM, like, e.g. a FED television device.

\subsection{Structure of this publication}

The goal of this study was therefore an up-to-date and comprehensive assessment of the ecological sustainability of an FED television device by the use of all these latest developments in the area of LCA, keeping the study in accordance with the ISO 14040 standard (ISO 2006). Therefore, this paper summarizes in section 2 the key elements of the goal and scope definition of our study, together with the most important data sources used for the LCA study of an FED television device. Section 3 then shows in a first part the results of the in-depth analysis of such an FED television device, followed by the results of a comparison with current display technologies used for television devices, and the timely evolution of the results for the FED television device over the past 5 years. In section 4, all these results are further analysed and discussed, and the resulting conclusions are summarized in the concluding section 5 .

\section{Methodology}

\subsection{Goal and scope definition}

\subsubsection{Objective}

The overall objective of this study is an ecological in-depth analysis of an FED television device by applying the latest developments in the area of LCA in accordance with the ISO 14040 standard (ISO 2006). Based on in-house experience in the area of consumer electronics (i.e. the FED model in Bauer et al. 2008, was established at Empa - and models for CRT, LCD and PDP devices from Empa are reported, e.g. in Hischier and Baudin 2010; Hischier et al. 2013), comparisons between this FED television device and television devices based on today's display technologies, but also the development of the data for the FED technology along a timeline 2008 to 2013 are established as a second and third element within this study.

Scope and examined system The scope is a traditional cradle to grave LCA study - from the supply of the raw materials used in the production, along the actual production and the subsequent use of the FED television device to the End-ofLife (EoL) treatment (i.e. dismantling, recycling, or disposal) at the end of the life of such a device. An overview of this system is shown in Fig. 1.

For all other television technologies, the models already published by the author (references see above) are used here. 
Fig. 1 Examined system for the cradle-to-grave LCA study of an FED television device. As background, the database ecoinvent v2.2 (ecoinvent Centre $2010)$ is used

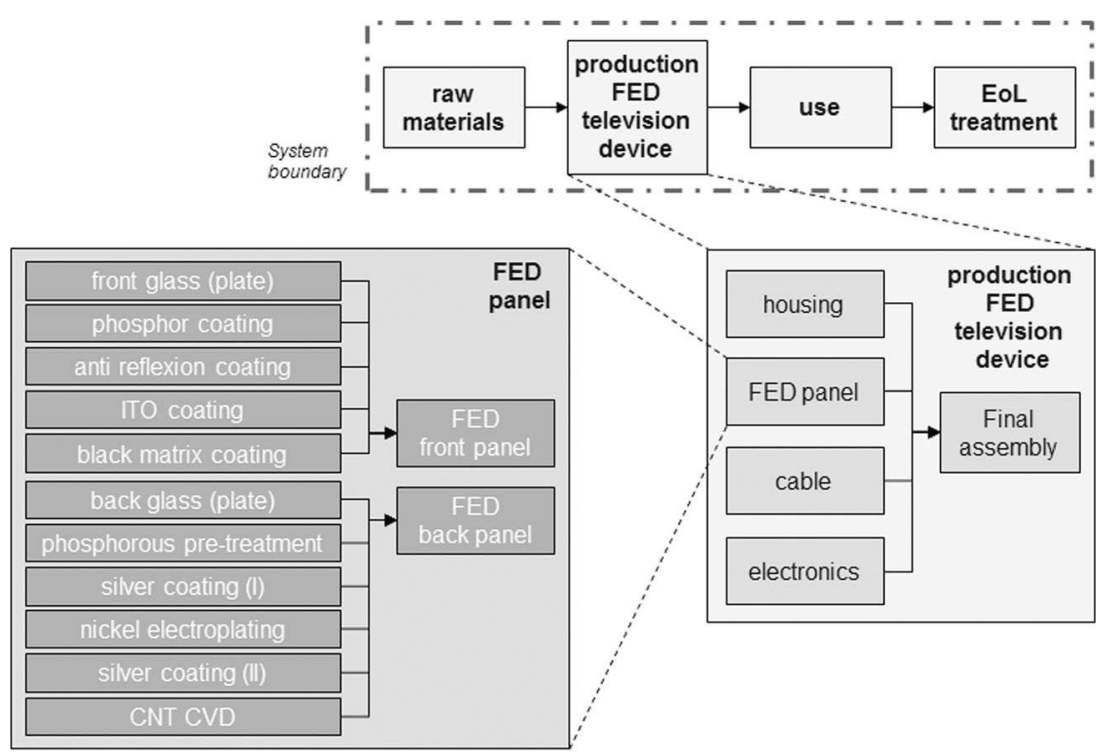

\subsubsection{Functional unit}

For the study of the FED television device, one entire device over its complete life cycle (using the use pattern described below) is considered as the functional unit. For the subsequent comparison with these other television devices mentioned above, "1 square-inch of display during $1 \mathrm{~h}$ of active use" is used as functional unit in order to take into account that the various devices exist in very different size ranges due to technological constraints. Such an area-based functional unit is the most appropriate choice for such a comparison, as according to DCE 2007, the energy consumption of a television device is about proportional to its surface size.

\subsubsection{Study object}

The study object is a 36-in. FED television device. This device is compared in a second part of the study with "typical" television devices of other technologies ("typical" concerning their size). Therefore, Table 2 summarizes key characteristics of all the television devices examined here. The derivation of the numbers for the FED television device is explained in more details in section 1 of the Electronic Supplementary Material of this paper.

\subsubsection{Data sources}

The main data sources for the foreground processes of the FED television device according to Fig. 1 are patents (e.g. Dean et al. 2005; Hwang et al. 2005) and the publication by Fink and co-workers comparing FED and SED technologies (Fink and Yaniv 2007). A comprehensive documentation of the here modelled FED television device and a complete list of used data sources can be found in the Electronic
Supplementary Material. In the background, data from the database ecoinvent v2.2 (ecoinvent Centre 2010) have been used.

For the other television devices taken into account in this study here (i.e. CRT, LCD, and PDP devices), models developed at Empa in the framework of former studies have been used (Hischier and Baudin 2010, for CRT and PDP-Hischier et al. 2013, for LCD). Actually, the FED device here is modelled in a way similar to that for those devices by, e.g. using the same background database (ecoinvent v2.2), thus yielding a dataset comparable to these other technologies.

\subsection{Life cycle inventory analysis of the FED television device}

\subsubsection{Production FED television device}

According to Hwang et al. 2005, and Dean et al. 2005, such an FED device could be split into the following main components (see lower part of Fig. 1): housing, FED panel, cable, and electronics. The values used here for the various elements are summarized in Table 3; more details about the derivation of these numbers, and their exact modelling-especially concerning the various coatings within the FED panel, can be found in the Electronic Supplementary Material.

\subsubsection{Use phase}

Active use of a television device for $4 \mathrm{~h}$ per day is assumed. For all remaining time (during a complete life-span of 8 years), this device is assumed to be turned "off" 4 weeks per year (the typical time of holidays in most European countries - and this seems to be the only realistic time for having such a device "really" turned off), while all other time, a television device is 
Table 2 Key characteristics of the television devices examined and compared in this study

\begin{tabular}{|c|c|c|c|c|}
\hline Specification & FED & LCD & PDP & CRT \\
\hline Screen size $\left[\right.$ inch $\left.^{\mathrm{a}}\right] /$ format & 36/16: 9 & $40 / 16: 9$ & 42/16: 9 & 32/16:9 \\
\hline Resolution (pixel $\times$ pixel) & $1,280 \times 768$ & $1,366 \times 768$ & $1,024 \times 768$ & n.a. ${ }^{b}$ \\
\hline Luminosity $\left[\mathrm{cd} / \mathrm{m}^{2}\right]$ & 500 & 500 & 1,400 & n.a. \\
\hline Contrast & $20,000: 1$ & $15,000: 1$ & $3,000: 1$ & n.a. \\
\hline Weight $[\mathrm{kg}]$ & 13.5 & 17.4 & 30.2 & 48.3 \\
\hline \multicolumn{5}{|l|}{ Electricity consumption [W] } \\
\hline - On & 70 & 138 & 303 & 115 \\
\hline - Stand-by & 1.7 & 1.7 & 1.6 & 1.8 \\
\hline Data source & Details in suppl. materials & Hischier et al. (2013) & Hischier and Baudin (2010) & Hischier and Baudin (2010) \\
\hline
\end{tabular}

${ }^{\mathrm{a}} 1 \mathrm{in.}=2.54 \mathrm{~cm}$

${ }^{\mathrm{b}}$ n.a. not applicable

assumed to be on "stand-by" only. The energy consumption of this "stand-by" time is attributed proportionally to the use phase (i.e. resulting in $5 \mathrm{~h}$ of "stand-by" per hour of active use). For the 4 weeks of "off", no energy consumption is assumed for each of the examined technologies. For the consumed electricity, as default value, the Swiss electricity mix is used here.

\subsubsection{End-of-life treatment}

For all television devices examined here, an end-of-life treatment in accordance with the European Waste Electric and

Table 3 Weight and modelling of the main components of a 36-in. FED television device

\begin{tabular}{|c|c|c|}
\hline Component & $\begin{array}{l}\text { Weight } \\
{[\mathrm{kg}]}\end{array}$ & Details and comments \\
\hline Housing & 4.6 & $\begin{array}{l}1.1 \mathrm{~kg} \text { ABS (injection moulding) }+3.5 \mathrm{~kg} \\
\text { aluminium (50 \% profiles, } 50 \% \text { sheet) }+ \\
0.02 \mathrm{~kg} \text { screws, as chromium steel (profiles). } \\
\text { Data derived from information for LCD } \\
\text { television screens (for details, see } \\
\text { supplementary materials) }\end{array}$ \\
\hline FED panel & 7.8 & $\begin{array}{l}5.8 \mathrm{~kg} \text { glass (front, rear panel, separator ribs) }+ \\
1.5 \mathrm{~kg} \text { aluminium (profile) }+500 \mathrm{~g} \text { electronics. } \\
\text { Data based on description of a } 36-\text { in. SED } \\
\text { panel in Fink and Yaniv } 2007 . \text { For the } \\
\text { (additional) coatings on both panel plates, see } \\
\text { supplementary materials. }\end{array}$ \\
\hline Cable & 0.4 & $\begin{array}{l}\text { Assumption: similar as to the PDP display-split } \\
\text { up into } 275 \mathrm{~g} \text { internal cable (as ribbon cable, } \\
\text { 20-pin) }+1.2 \mathrm{~m} \text { electricity cable (+plugs). Data } \\
\text { derived from the model for a PDP in Hischier } \\
\text { and Baudin (2010). }\end{array}$ \\
\hline Electronics & 0.7 & $\begin{array}{l}\text { Modelled as "printed wiring board, mixed } \\
\text { mounted, unspec., solder mix". Amount data } \\
\text { derived from information for LCD television } \\
\text { screens (for details, see supplementary } \\
\text { materials) }\end{array}$ \\
\hline
\end{tabular}

Electronic Equipment (WEEE) Directive was modelled, using the various WEEE treatment datasets in ecoinvent (described in detail in Hischier et al. 2007). In this study, it is assumed that all the devices are in a first step manually depolluted, then mechanically treated (i.e. passed through a shredder). For the depollution, the rules from Hischier et al. (2007; part V, Tab. 4.6) are used; the further mechanical treatment is modelled according to the procedure described in Hischier et al. (2007; part V, chapter 4.3.5). More details about the resulting fractions for all the television display technologies are reported in the Electronic Supplementary Material.

For the recycled materials, the avoided burden approach is applied-i.e. a bonus is given that is equivalent to the environmental load from the primary production efforts for a similar amount of material (e.g. primary steel production in a converter furnace), minus the recycling efforts for the respective material (e.g. the efforts of secondary steel production in an electric arc furnace).

\subsubsection{Modelling of carbon nanotubes along the life cycle}

All the CNT flows are modelled in a separate way in this study. Their production has been modelled with information from the patent for FED technology (Hwang et al. 2005) and it has been amended with data from other literature sources dealing with production of CNTs in general (e.g. Healy et al. 2008; Isaacs et al. 2010). More details about the modelling of CNT production can be found in the Electronic Supplementary Material.

In general, release concentrations and/or amounts of CNTs along the life cycle of a product have been studied only to a very limited extent - experimentally and/or analytically (Gottschalk et al. 2013). In the present case, based on the description of the CVD process technology in Plata 2009, it can be deduced that during the production no emissions of CNTs are 
taking place. A similar assumption can be made for the use phase of such a television device, as the CNTs are embedded inside the FED panel. Obviously, the situation is very different in the end-of-life treatment of such devices, where CNTs could be released to nature, as the FED panel is mechanically destroyed. As described in the Electronic Supplementary Material, this disposal step is modelled as $50 \%$ similar to CRT glass tubes and $50 \%$ similar to PDP modules.

- CRT case: Whenever an FED panel is treated in a manner similar to the coated CRT glass, the CNTs are washed off together with all other coatings; and this wet material is then incinerated. Gottschalk and co-workers modelled in a former study the incineration step of CNTs by assuming that $98 \%$ of the CNTs are burned (i.e. transformed into $\mathrm{CO}_{2}$ ), and that the remaining $2 \%$ go in the slag compartment (Gottschalk et al. 2010). In a worst case scenario, it could be assumed then that $100 \%$ of this amount in the slag compartment would be emitted into the ground-water.

- PDP case: When using a similar treatment as for plasma panels, i.e. putting such a panel into a shredder installation, the release of (at least one part) of the CNTs as emissions to air has to be assumed. Hence, for a worst case scenario, a release into air of all the CNTs contained in such a panel is assumed here.

All these assumptions lead - for a worst case scenario - to a total amount of $1.25 \mathrm{mg}$ of CNTs emitted into air and $0.025 \mathrm{mg}$ of CNTs emitted into ground-water during the complete life cycle of a FED television device. In accordance with the modelling framework for releases of MNM reported in Hischier 2014, the released amount is further characterised in terms of shape and size (distribution). Based on the description of the production of CNTs in the FED screen (as detailed in the Electronic Supplementary Material) and due to a lack of further information related to the behaviour of CNTs in the EoL treatment activities described above, it is assumed here that $100 \%$ of the released CNTs is of fibrous shape and has an average diameter $\left(D_{\text {Avg }}\right)$ of $50 \mathrm{~nm}$, with a maximum length $(\mathrm{L})$ of $2.5 \mu \mathrm{m}$.

\subsection{Impact assessment}

Two of the most up-to-date methods in this area have been applied here-i.e. the ReCiPe (Goedkoop et al. 2012) and the USEtox method (see, e.g. Rosenbaum et al. 2008), the consensus model for the assessment of toxicity in LCA.

The latter one is used here, as releases of nanoparticles could lead to toxicological concerns; and a recent publication has reported for the first time characterisation factors (CF) for the ecotoxicity potential of CNT releases (Eckelman et al. 2012); factors that can be used for the assessment of the above described amount of CNTs released in the end-of-life treatment. ReCiPe, on the other hand, is an up-to-date, convenient and consistent way of presenting results on a midpoint and on an endpoint level. In this study, the $\mathrm{CF}$ for $\mathrm{PM}_{10}$ emissions is also applied to releases of CNTs in the calculation of the impact category "PMFP, particulate matter formation potential", in order to get an idea of the relevance of these CNT releases, in comparison with all remaining $\mathrm{PM}_{10}$ releases.

So far however, none of the LCIA methods contains a CF for the impact of CNT releases on human health or human toxicity, respectively - an impact that due to the above described shape (i.e. fibrous form) releases from such CNTs most probably have however.

\section{Results}

\subsection{The overall life cycle of a FED television device}

The examination of the environmental impacts along the complete life cycle of the 36-in. FED television device specified here - partly reported in Table 4-results in the environmental impacts shown in Fig. 2.

These results show a clear dominance-independently from the particular LCIA factor considered-of the production phase of the television device. This life-stage is responsible for $70 \%$ (in the case of "ozone depletion", ODP) up to almost $95 \%$ (for "metal depletion", MDP) of the overall impact. The relevance of any CNT releases in the end-of-life treatment is shown in an extension in the right part of Fig. 2. While for the ReCiPe midpoint factor PMFP these releases are not even visible under such strong enlargement, Fig. 2 shows a small impact in the case of the USEtox ecotoxicity potential. The resulting impact is shown with both CFs reported in Eckelman et al. 2012. Actually, the impacts from CNT release are negligible because even with the high, conservative $\mathrm{CF}$ an impact results due to CNT release that is only about $0.003 \%$ compared to the overall ecotoxicity potential of the examined FED television device. An indication concerning the influence on the human toxicity potential is missing so far due to a lack of respective CFs.

Next, the production of the FED television device is examined in more details. Figure 3 shows these results.

The production phase is again dominated - across all LCIA factors examined here - by one single element, the electronic (i.e. the various printed wiring boards in such a device). From the remaining elements, the estimation for the production efforts (assumed here as $75 \%$ of the assembly efforts for an LCD screen in ecoinvent-details see Hischier et al. 2007) 
Table 4 Extract of emission and resource consumption factors out of the cumulative life cycle inventory results for the life cycle of a 36-in. FED television device

\begin{tabular}{|c|c|c|c|c|c|c|c|}
\hline & & \multirow[t]{2}{*}{ Total } & \multicolumn{2}{|l|}{ Production } & \multirow[t]{2}{*}{ Use } & \multicolumn{2}{|c|}{ End-of-Life Treatment } \\
\hline & & & FED panel & Remaining parts & & Efforts & Benefits \\
\hline \multicolumn{8}{|l|}{ (a) Resource consumption } \\
\hline Aluminium, in ground & $\mathrm{kg}$ & $\begin{array}{l}-4.13 \mathrm{E}-01 \\
8.39 \mathrm{E}+01 \\
1.09 \mathrm{E}+02 \\
9.22 \mathrm{E}+01 \\
1.09 \mathrm{E}+00 \\
5.94 \mathrm{E}+01 \\
1.59 \mathrm{E}+02 \\
4.51 \mathrm{E}+00 \\
3.27 \mathrm{E}+01 \\
1.43 \mathrm{E}+03\end{array}$ & $1.48 \mathrm{E}-00$ & $3.26 \mathrm{E}+00$ & $5.41 \mathrm{E}-02$ & $2.34 \mathrm{E}-03$ & $-5.21 \mathrm{E}+00$ \\
\hline Calcite, in ground & $\mathrm{kg}$ & $8.39 \mathrm{E}+01$ & $3.39 \mathrm{E}+01$ & $4.88 \mathrm{E}+01$ & $3.17 \mathrm{E}+00$ & $3.36 \mathrm{E}-01$ & $-2.29 \mathrm{E}+00$ \\
\hline Coal, brown, in ground & $\mathrm{kg}$ & $1.09 \mathrm{E}+02$ & $3.29 \mathrm{E}+01$ & $4.40 \mathrm{E}+01$ & $3.74 \mathrm{E}+01$ & $5.97 \mathrm{E}-01$ & $-5.65 \mathrm{E}+00$ \\
\hline Coal, hard, in ground & $\mathrm{kg}$ & $9.22 \mathrm{E}+01$ & $2.20 \mathrm{E}+01$ & $5.61 \mathrm{E}+01$ & $2.27 \mathrm{E}+01$ & $8.16 \mathrm{E}-01$ & $-9.35 \mathrm{E}+00$ \\
\hline Copper, in ground & $\mathrm{kg}$ & $1.09 \mathrm{E}+00$ & $3.32 \mathrm{E}-01$ & $7.64 \mathrm{E}-01$ & $3.80 \mathrm{E}-01$ & $6.36 \mathrm{E}-02$ & $-4.52 \mathrm{E}-01$ \\
\hline Gas, natural, in ground & $\mathrm{Nm} 3$ & $5.94 \mathrm{E}+01$ & $2.01 \mathrm{E}+01$ & $2.73 \mathrm{E}+01$ & $1.33 \mathrm{E}+01$ & $1.48 \mathrm{E}+00$ & $-2.75 \mathrm{E}+00$ \\
\hline Gravel, in ground & $\mathrm{kg}$ & $1.59 \mathrm{E}+02$ & $5.71 \mathrm{E}+01$ & $9.23 \mathrm{E}+01$ & $1.52 \mathrm{E}+01$ & $2.56 \mathrm{E}+00$ & $-8.56 \mathrm{E}+00$ \\
\hline Iron, in ground & $\mathrm{kg}$ & $4.51 \mathrm{E}+00$ & $1.01 \mathrm{E}+00$ & $2.40 \mathrm{E}+00$ & $1.36 \mathrm{E}+00$ & $4.95 \mathrm{E}-02$ & $-3.09 \mathrm{E}-01$ \\
\hline Oil, crude, in ground & $\mathrm{kg}$ & $3.27 \mathrm{E}+01$ & $1.29 \mathrm{E}+01$ & $2.08 \mathrm{E}+01$ & $4.85 \mathrm{E}+00$ & $3.33 \mathrm{E}-01$ & $-6.21 \mathrm{E}+00$ \\
\hline $\begin{array}{l}\text { Energy, potential, converted } \\
\text { (in hydropower reservoir) } \\
\text { (b) Emission to air }\end{array}$ & MJ & $1.43 \mathrm{E}+03$ & $1.36 \mathrm{E}+02$ & $2.59 \mathrm{E}+02$ & $1.19 \mathrm{E}+03$ & $5.89 \mathrm{E}+00$ & $-1.55 \mathrm{E}+02$ \\
\hline Carbon dioxide, fossil & $\mathrm{kg}$ & $5.39 \mathrm{E}+02$ & $1.62 \mathrm{E}+02$ & $2.91 \mathrm{E}+02$ & $1.16 \mathrm{E}+02$ & $1.60 \mathrm{E}+01$ & $-4.67 \mathrm{E}+01$ \\
\hline Sulphur dioxide & $\mathrm{kg}$ & $2.68 \mathrm{E}+00$ & $9.27 \mathrm{E}-01$ & $1.50 \mathrm{E}+00$ & $4.31 \mathrm{E}-01$ & $2.34 \mathrm{E}-02$ & $-1.93 \mathrm{E}-01$ \\
\hline Nitrogen oxides & $\mathrm{kg}$ & $1.52 \mathrm{E}+00$ & $5.33 \mathrm{E}-01$ & $8.46 \mathrm{E}-01$ & $2.25 \mathrm{E}-01$ & $1.77 \mathrm{E}-02$ & $-1.01 \mathrm{E}-01$ \\
\hline Methane, fossil & $\mathrm{kg}$ & $1.22 \mathrm{E}+00$ & $3.00 \mathrm{E}-01$ & $7.74 \mathrm{E}-01$ & $2.13 \mathrm{E}-01$ & $1.31 \mathrm{E}-02$ & $-7.82 \mathrm{E}-02$ \\
\hline PAH, polycyclic aromatic hydrocarbons & $\mathrm{kg}$ & $-6.91 \mathrm{E}-06$ & $1.12 \mathrm{E}-04$ & $2.65 \mathrm{E}-04$ & $1.10 \mathrm{E}-05$ & $8.01 \mathrm{E}-07$ & $-3.96 \mathrm{E}-04$ \\
\hline CNT, carbon nanotubes & $\mathrm{kg}$ & $1.25 \mathrm{E}-06$ & - & - & - & $1.25 \mathrm{E}-06$ & - \\
\hline \multicolumn{8}{|l|}{ (c) Emission to water } \\
\hline COD, chemical oxygen demand & $\mathrm{kg}$ & $1.03 \mathrm{E}+01$ & $4.02 \mathrm{E}+00$ & $6.29 \mathrm{E}+00$ & $8.30 \mathrm{E}-02$ & $8.19 \mathrm{E}-02$ & $-1.62 \mathrm{E}-01$ \\
\hline Chloride & $\mathrm{kg}$ & $4.02 \mathrm{E}+00$ & $1.31 \mathrm{E}+00$ & $2.30 \mathrm{E}+00$ & $7.29 \mathrm{E}-01$ & $5.72 \mathrm{E}-02$ & $-3.82 \mathrm{E}-01$ \\
\hline Sulphate & $\mathrm{kg}$ & $1.17 \mathrm{E}+02$ & $4.81 \mathrm{E}+01$ & $6.02 \mathrm{E}+01$ & $1.05 \mathrm{E}+01$ & $4.60 \mathrm{E}-01$ & $-2.72 \mathrm{E}+00$ \\
\hline Ammonium, ion & $\mathrm{kg}$ & $2.99 \mathrm{E}-01$ & $1.37 \mathrm{E}-03$ & $2.96 \mathrm{E}-01$ & $1.41 \mathrm{E}-03$ & $1.44 \mathrm{E}-05$ & $-1.23 \mathrm{E}-04$ \\
\hline Nickel, ion & $\mathrm{kg}$ & $5.31 \mathrm{E}-02$ & $1.91 \mathrm{E}-02$ & $2.49 \mathrm{E}-02$ & $9.56 \mathrm{E}-03$ & $1.94 \mathrm{E}-03$ & $-2.40 \mathrm{E}-03$ \\
\hline Cobalt, ion & $\mathrm{kg}$ & $4.52 \mathrm{E}-02$ & $1.92 \mathrm{E}-02$ & $2.37 \mathrm{E}-02$ & $3.15 \mathrm{E}-03$ & $2.54 \mathrm{E}-04$ & $-1.01 \mathrm{E}-03$ \\
\hline Vanadium, ion & $\mathrm{kg}$ & $1.32 \mathrm{E}-02$ & $5.47 \mathrm{E}-03$ & $8.17 \mathrm{E}-03$ & $1.44 \mathrm{E}-03$ & $6.30 \mathrm{E}-05$ & $-2.80 \mathrm{E}-03$ \\
\hline CNT, carbon nanotubes & $\mathrm{kg}$ & $2.50 \mathrm{E}-08$ & - & - & - & $2.50 \mathrm{E}-08$ & - \\
\hline
\end{tabular}

shows a clearly higher impact than the other parts of the device, i.e. the housing or the FED panel.

Figure 4 shows the latter-i.e. the FED panel-in more details, as this element contains the CNTs. However, even in such a focussed diagram, the contribution from the production and application of CNTs (summarized as "CNT CVD") is very minor; the process is dominated either by the glass production (in case of impact factors FDP, GWP, and ODP) or the silver paste used (in case of MDP, PMFP, ETP, and HTP). All in all, production and application efforts of CNTs do not influence at all the LCA results of such a television device.

\subsection{Comparison with today's television devices}

In a second step, this FED television device was compared with the three technologies on the market today for television devices - i.e. the CRT, the LCD, and the PDP technology. Based on a similar use pattern for all these technologies, the resulting environmental impacts for $1 \mathrm{~h}$ of watching television 


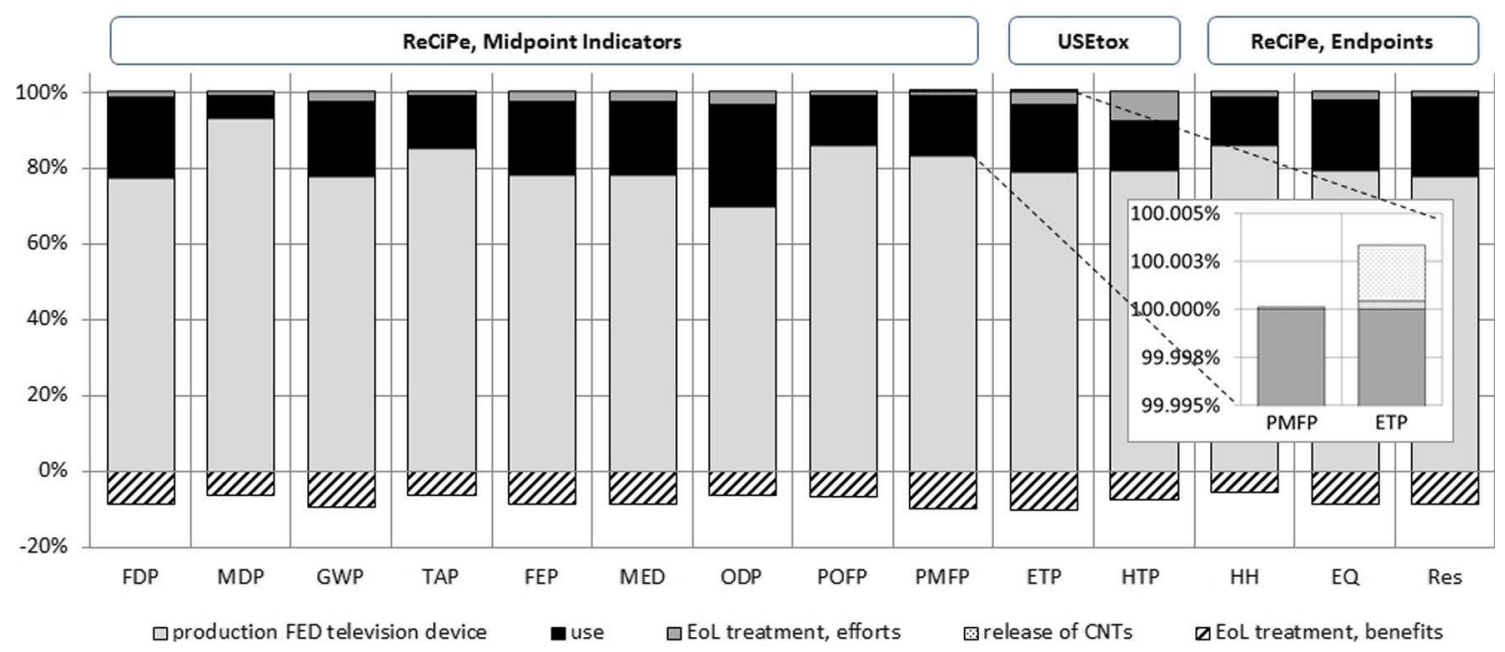

Fig. 2 Environmental impacts of a 36-in. FED television device along the complete life cycle - split into the life stages shown in the upper part of Fig. 1; shown are [ReCiPe Midpoints] fossil depletion potential (FDP), metal depletion potential $(M D P)$, global warming potential $(G W P)$, terrestrial acidification potential $(T A P)$, freshwater eutrophication potential $(F E P)$, marine eutrophication potential $(M E P)$, ozone depletion potential

were calculated. The results of this comparison are shown on a "per square-inch" basis in order to make the four technologies and their-due to technical restrictions - different screen sizes comparable. According to DCE (2007), the three existing technologies have an electricity consumption in the use phase that is directly proportional to the surface of the screen; hence this latter can be used as functional unit for this technology comparison. The results in Fig. 5 show the relative impact per one square-inch of screen and per hour of watching television for the three damage systems of the ReCiPe Endpoints method.

All four technologies are dominated by the production of the respective device - the use phase (based on the Swiss electricity mix!) shows a clearly lower impact. When using a
$(O D P)$, photochemical oxidant formation potential $(P O F P)$, particulate matter formation potential $(P M F P)$, [USEtox] ecotoxicity potential $(E T P)$, human toxicity potential $(H T P)$, [ReCiPe End-points] damage to human health $(H H)$, on ecosystem quality $(E Q)$, and resource consumption (Res)

more polluting electricity mix (e.g. the European UCTE mix), the differences between the various technologies become more accentuated. Changes are due to a higher impact of the use phase (see small picture within Fig. 5); and in some cases (like, e.g. for all three shown damage categories in the case of the PDP; in the case of the resource damage factor also for the CRT), the use phase now becomes even more important than the production of the device.

The FED television device shows for all damages categories the lowest impact, independently from the actual electricity mix used. The impacts from the other three technologies do not differ very much on the relative scale per square-inch. A similar analysis for the USEtox indicator "ecotoxicity potential"-bearing in mind that CNT releases add less than

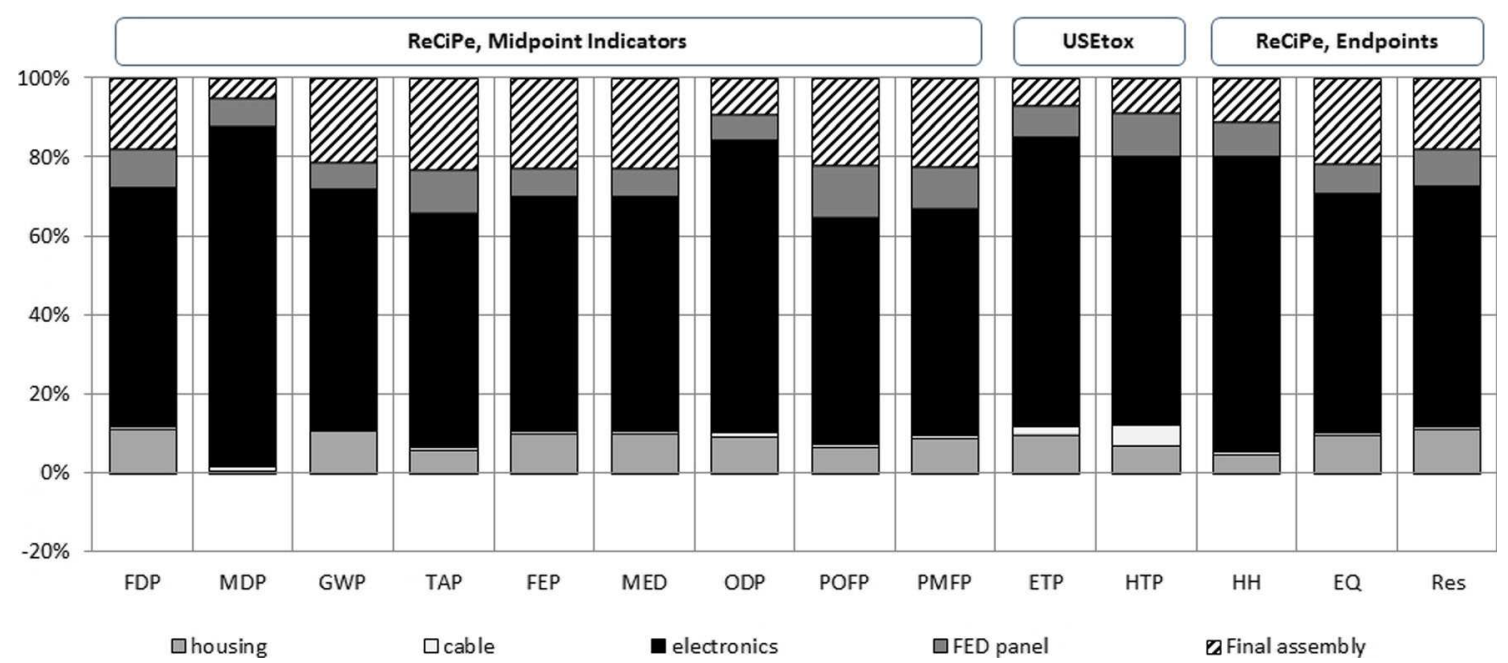

Fig. 3 Environmental impacts of the production of a 36-in. FED television. For an explanation of the abbreviations of the reported LCIA factors, see Fig. 2 


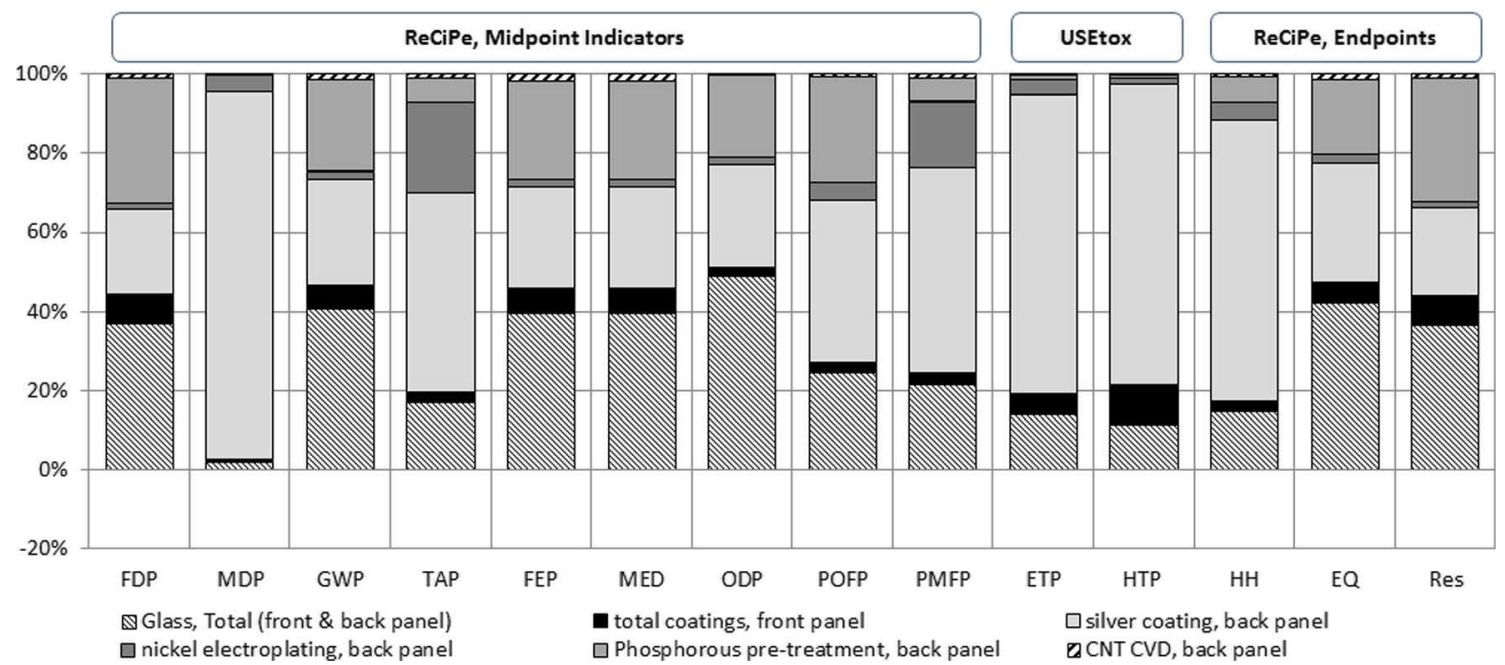

Fig. 4 Environmental impacts of the production of the FED panel (explanation of the abbreviations of the reported LCIA factors is given in Fig. 2)

$0.005 \%$ to the overall impact (see Fig. 2)-results in the picture shown in Fig. 6.

Figure 6 shows a more or less similar picture, as the three damage categories of the ReCiPe Endpoints method - i.e. the use of a FED television device leads to the lowest environmental impact, followed by the LCD, the PDP and the CRT device. The impact of CNT releases - even in the case of $100 \%$ of release (i.e. almost twice the amount used in the calculation) - is not visible, compared to all the other impacts in the production and in the use phase.

\subsection{Temporal development within the LCA of the FED technology}

At Empa, an FED television device has been examined two times - a first time for the 2nd case study reported in Bauer et al. 2008, and a second time for the case study reported here.
In-between these two studies, there is a time span of more than 5 years; a lapse of time that has seen major developments in the area of LCA, like, e.g. ecoinvent $\mathrm{v} 2$ (and its data covering the electronics sector) or the publication of first inventory data about the CNT production (Healy et al. 2008; Isaacs et al. 2010). In other words, the first modelling had been done in an era having only one single dataset for the whole electronics sector available and before the publication of CNT LCI data. As a consequence, the comparison between the two calculations shows the influence of the developments on the level of inventory modelling (e.g. expansion of background databases, MNM modelling rules, etc.). The comparison is shown in Fig. 7. Due to different screen sizes, the results for four different midpoint indicators from the CML method (Guinee et al. 2001), used in Empa's first case study of the FED technology (Bauer et al. 2008), are shown per square-inch of screen surface.
Fig. 5 Impacts (damage systems of ReCiPe Endpoints; shown in "points") of $1 \mathrm{~h}$ of watching television with the various devices - shown are relative results per square-inch of surface of each single device used with the Swiss electricity mix (big picture) or the use with the European UCTE (Union for the Co-ordination of Transmission of Electricity) electricity mix (small picture)

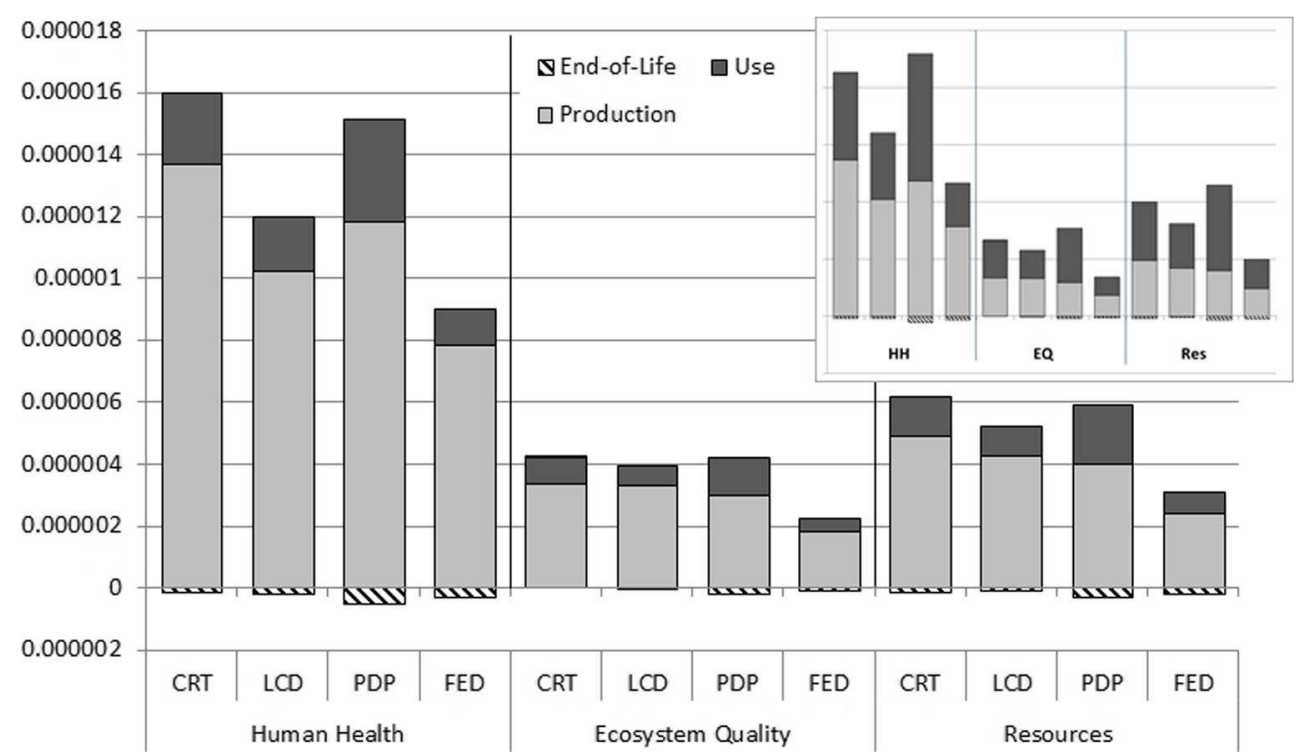


Fig. 6 Impacts (expressed as "ecotoxicity potential" according to the USEtox method) of $1 \mathrm{~h}$ of watching television with the various devices - relative results per square-inch of surface of each single device used with the Swiss electricity mix are shown (left) and the use with the European UCTE electricity mix (right)

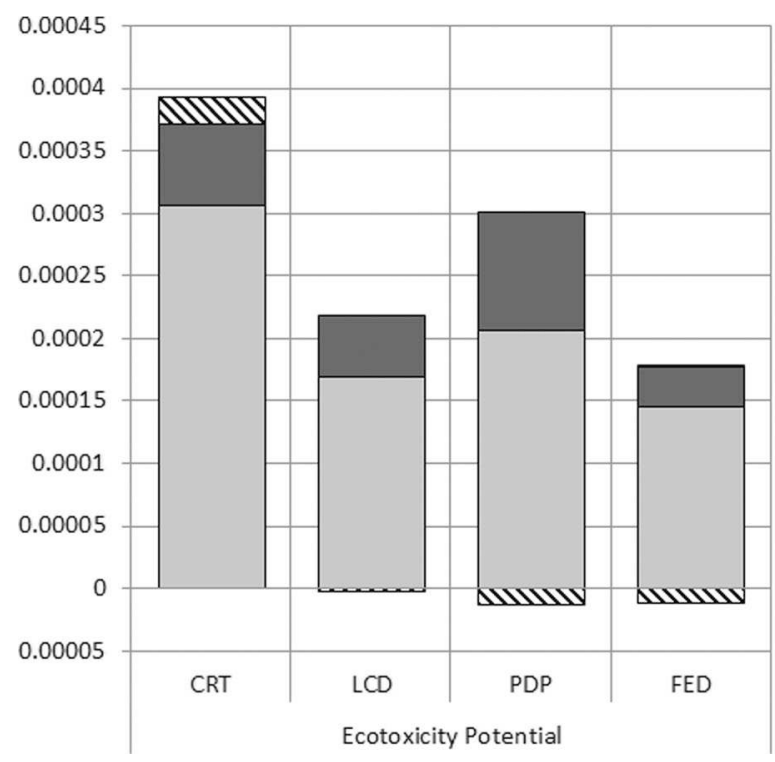

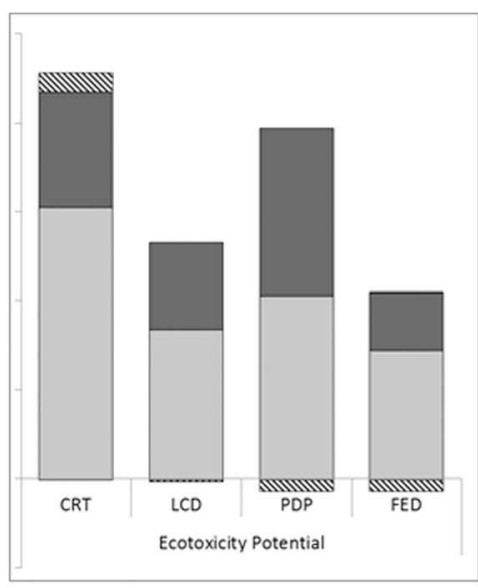

BCNT releases

\$End-of-Life

$\square$ Use

$\square$ Production
The results in Fig. 7 show an astonishing similarity in the results from the two studies; apparently the more adequate modelling that is possible today has a quite similar influence on all three screen technologies included here (see, e.g. the factor "ozone depletion"-factor that shows a very small difference between 2008 and 2013 in case of FED and CRT). An examination of toxicity factors (and like this, an inclusion of the above estimated releases of CNTs) is not possible; respective calculations for the data published 2008 are not available.

\section{Discussion}

\subsection{FED and today's television devices}

The resulting picture for the FED television device is a rather clear picture-despite all the uncertainties concerning the release (and the respective assessment) of CNTs during the various life stages of such a device. Actually, this FED television device shows a typical result for more energy efficient technologies - the production phase of the device (i.e. the device as infrastructure) becomes increasingly relevant. CNTs as a new element in this infrastructure do not show any relevance on the level of production - the printed wiring board and the ICs continue to be the most relevant elements having the highest environmental impact within such an ICT device. In competition to the various further display technologies used today in television devices, the shown comparison on the level of the three damage factors of the $\mathrm{ReCiPe}$ Endpoint method results in a quite clear environmental advantage for the FED television device - in total, and also on the level of the infrastructure and with the use phase taken into account separately. Actually, the FED television device proves that having a
Fig. 7 Relative impact per square-inch of various television technologies (relative, as the LCD device is normalized to $100 \%$ for each of the shown LCIA factors) for four different midpoint factors. _ _ _ - shows results from the former study (taken out of Fig. 10 in Bauer et al. 2008)

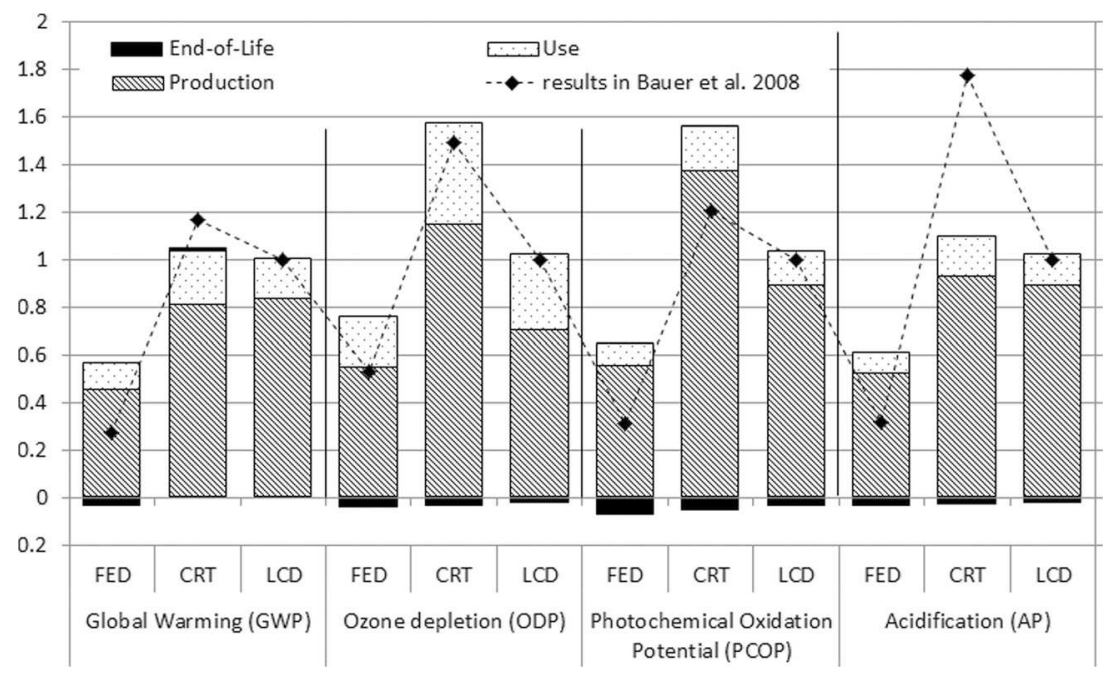


simpler technical structure, and being less power consuming, are valuable arguments for being a more environmentally friendly technology.

\subsection{Temporal development within the LCA of the FED technology}

This seeming accordance between the simple model used in Bauer et al. (2008), and the much more detailed model of this study is actually the result of several, overlapping effects. A detailed analysis of the results in Bauer et al. (2008), shows that the results are dominated (a) by the use phase via the electricity consumption of the device (assumed as $75 \%$ of the consumption of an LCD display) and (b) by the CNT production. Based on the knowledge acquired since then, an amount per surface that was much too high, and an energy consumption for the CVD process itself that was much too high were integrated into this first model. In the "new" model, due to more detailed background data for electronic components, the printed wiring boards have a much higher impact than in the old model. In combination with current data about the energy consumption of a 36-in. FED television and more realistic data concerning the amount of CNTs that are used in such a device, this results in the end in a ratio between LCD and FED in the same order of magnitude for both studies. But it has to be stipulated clearly here, that the current model is much more accurate than the simple model for the FED technology established for Bauer et al. 2008.

\subsection{Critical view of the LCI framework for nanoparticle releases}

In accordance with the modelling framework for releases of MNM reported in Hischier 2014, the released amount of CNTs has been further characterised here in terms of shape and size (distribution). However, this additional information cannot be used actively in the assessment due to the fact that only one single CF for the ecotoxicological effects of CNTs (in Eckelman et al. 2012) is reported so far. It is thus not yet possible to judge this framework mentioned above. At the same time, this example shows quite well the actual dependency of LCI and LCIA - and the need for further specifications on both levels. The rather simple and straight-forward assumptions for the releases of CNTs into the environment used here during the End-of-Life phase of the FED device leads in the case of the "ecotoxicity potential"-using the higher value reported in Eckelman et al. 2012, as the CF for the CNT releases - to a hardly visible increase on the order of $0.003 \%$. And even a worst case, assuming a release of the complete CNT content to air, would only double this resulti.e. result in a $0.006 \%$ higher impact of a FED device; in other words, (still) would have no influence on the overall ecotoxicity result of such a screen. In the end, the case examined here is an example that rather confirms the "general opinion" about MNM-i.e. that its use "will allow a more efficient use of materials and energy and reduce waste and pollution" (see, e.g. Bauer et al. 2008).

However, this rather large range for the ecotoxicity $\mathrm{CF}$ of CNT releases (in Eckelman et al. 2012) is a sign in favour of the request for additional specifications of this kind of emissions (as also stipulated in Hischier 2014) - despite the fact that even the higher CF value does not lead to a relevant impact of the CNTs in this specific case study. On a longterm (having in mind the "exact" $\mathrm{CF}$ values in case of bulk emissions - and the large variety between different forms and types of CNTs, and their differences in environmental behaviour), there will be several different CFs for different sizes/ forms of CNTs and if this is only in order to narrow the range between a conservative and a realistic value each time.

An additional point that stresses the development of specific CFs for MNM is the influence shown here (i.e. actually the non-influence, as shown in Fig. 3) of a pure mass-based factor like the "particulate matter formation potential (PMFP)". A simple application of the $\mathrm{PM}_{10}$-CF on MNM (and according to the definition of $\mathrm{PM}_{10}, \mathrm{MNM}$ - sometimes called $\mathrm{PM}_{0.1}$ - belong to the $\mathrm{PM}_{10}$ substances) shows that due to the very small amount of used/released MNM they are in such a mass-based weighting as to be of no importance and relevance at all.

\section{Conclusions and outlook}

The study gives - as far as this is possible, based on the current state of the development of the LCA framework for an application in the area of MNM - a comprehensive and upto-date overview of the ecological assessment of MNMcontaining ICT devices. For the examined device, it could be concluded that an FED television device has an environmental advantage over the three currently sold television display technologies; this is valid for traditional impact assessment categories (like, e.g. Global Warming, or Acidification) as well as for the aspect of "ecotoxicity". Due to methodological lacks, the assessment in the area of human toxicity does not show a comprehensive picture yet; respective CFs for releases of MNM are missing in this area. However, independently from these results, today in industry, the development of FED television devices has been abandoned by all major producers; instead they already turned towards other FPD technologies (like, e.g. OLED) for tomorrow's television devices.

In a next step, these new FPD technologies (OLED, etc.) should be assessed in a similar manner; ideally in an as early phase of the development as possible. At least some of these FPD technologies in development are also based on the 
application of MNM - and thus, need to be evaluated carefully; in order to ensure that they result, similar as the FED technology, in ecological advantages when compared to the current display technologies.

Concerning the general issue of evaluating MNM applications in LCA studies, it could be deducted from this study here that an adequate integration of releases of MNM during the life cycle is necessary for a comprehensive evaluation. The case here-although it results in no relevance for this kind of releases - has shown once more how important it is that the LCIA community develops in a systematic way CFs (in the areas of ecotoxicity and human toxicity) for a proper integration of releases of the most important MNM into comprehensive LCA studies.

\section{References}

Andrae ASG, Andersen O (2010) Life cycle assessments of consumer electronics - are they consistent? Int J Life Cycle Assess 15(8):827836

Aoe T (2003) Case study for calculation of factor X (Eco-Efficiency)comparing CRT TV, PDP TV and LCD TV. In: EcoDesign Conference, Tokyo (Japan), December 8 to 11, 20032003

Bauer C, Buchgeister J, Hischier R, Poganietz WR, Schebek L, Warsen J (2008) Environmental prospects in products - a framework for life cycle thinking on nano scales. J Clean Prod 16(8-9):910-926

BfS (2013) Statistik Schweiz - Medienindikatoren / Informationsgesellschaft - Indikatoren Haushalte und Bevölkerung - IKT-Ausstattung. Bundesamt für Statistik, BfS. www.bfs.admin.ch. Accessed February 62013

Chalamala BR, Wei Y, Gnade BE (1998) FED up with fat tubes. IEEE Spektrum April: 42-51

Coll BF, Dean KA, Howard E, Johnson SV, Johnson MR, Jaskie JE (2006) Nano-emissive display technology for large-area HDTV. J Soc Inf Disp 14(5):477-485

DCE (2007) Television energy rating labels: the case, and proposal, for MEPS and labelling televisions - discussion paper. Digital CEnergy (DCE), Leura (Australia)

Dean KA (2007) Nanotube displays - a new era. Nat Photonics 1:273275

Dean KA (2010) Nanotube field emission displays: nanotube integration by direct growth techniques. In: Saito Y (ed) Carbon nanotube and related field emitters: fundamental and applications. Wiley, Weinheim, pp 311-331

Dean KA, Coll BF, Talin AA, Von Allmen PA, Wei Y, Rawlett AM, Stainer M (2005) Field emission display and methods of forming a field emission display. Schaumburg (IL, USA) Patent

Eckelman MJ, Mauter MS, Isaacs JA, Elimelech M (2012) New perspectives on nanomaterial aquatic ecotoxicity: production impacts exceed direct exposure impacts for carbon nanotubes. Environ Sci Technol 46:2902-2910

ecoinvent Centre (2010) ecoinvent data v2.2. Swiss Centre for Life Cycle Inventories, Dübendorf, Switzerland

ETSI (2011) Life Cycle Assessment (LCA) of ICT equipment, networks and services; general methodology and common requirements. Technical Standard 103 199, V1.1.1. European Telecommunications Standards Institute (ETSI), Environmental Egnineering (EE), Sophia Antipolis (France)
Feng C, Ma XQ (2009) The energy consumption and environmental impacts of a color TV set in China. J Clean Prod 17(1):13-25

Fink R, Yaniv Z (2007) Displays: a closer look at SED, FED technologies. EE Times-Asia: 1-4

Fink RL, Yaniv Z, Thuesen LH, Pavlovsky I (2007) Technical comparison between SED and FED. http://www.appliednanotech.net/tech/ cnt_displays.php

Goedkoop M, Heijungs R, Huijbregts MAJ, de Schreyver A, Struijs J, Van Zelm R (2012) ReCiPe 2008 - A life cycle impact assessment method which comprises harmonised category indicators at the midpoint and the endpoint level. First edition (revised) / Report I: Characterisation. VROM - Ministery of Housing Spatial Planning and Environment, Den Haag

Gottschalk F, Sonderer T, Scholz RW, Nowack B (2010) Possibilities and limitations of modeling environmental exposure to engineered nanomaterials by probabilistic material flow analysis. Environ Toxicol Chem 29(5):1036-1048

Gottschalk F, Sun TY, Nowack B (2013) Environmental concentrations of engineered nanomaterials: review of modeling and analytical studies. Environ Pollut 181:287-300

Gurski J, Quach LM (2005) Display technology overview. Lytica White Paper. Lytica Inc., Ottawa

Healy ML, Dahlben LJ, Isaacs JA (2008) Environmental assessment of single-walled carbon nanotube processes. J Ind Ecol 12(3):376-393

Hischier R (2014) Life cycle assessment of manufactured nanomaterials: inventory modelling rules and application example. Int J Life Cycle Assess 19(4):838-849

Hischier R, Baudin I (2010) LCA study of a plasma television device. Int J Life Cycle Assess 15:428-438

Hischier R, Walser T (2012) Environmental sustainability assessment of engineered nanomaterials: state of art \& strategies to overcome existing gaps. Sci Total Environ 425:271-282

Hischier R, Classen M, Lehmann M, Scharnhorst W (2007) Life cycle inventories of electric and electronic equipment: production, use and disposal. Swiss Centre for Life Cycle Inventories, Empa-TSL, Dübendorf, Switzerland

Hischier R, Keller M, Lisibach R, Hilty LM mat - an ICT application to support a more sustainable use of print products and ICT devices. In: Hilty LM, Aebischer B, Andersson G, Lohmann W (eds) ICT4S 2013: Proceedings of the First International Conference on Information and Communication Technologies for Sustainability, ETH Zürich (Switzerland), 2013. doi:10. 3929/ethz-a-007337628

Hwang C-L, Ting J, Chiang J-S, Chuang C (2005) Process of Direct Growth of Carbon Nanotubes on a Substrate at Low Temperature. United States of America Patent US 6,855,376 B2

IPTS (2003) Environmental, technical and market analysis concerning the eco-design of television devices. European Commission, Joint Research Centre (JRC)-Institute for Prospective Technological Studies (IPTS), Sevilla (Spain)

Isaacs JA, Tanwani A, Healy ML, Dahlben LJ (2010) Economic assessment of single-walled carbon nanotube processes. J Nanopart Res 12:551-562. doi:10.1007/s11051-009-9673-3

ISO (2006) Environmental management-life cycle assessmentprinciples and framework. International Standardization Organization (ISO), European Standard EN ISO 14'040, Geneva, Switzerland

Leung H (2008) Display market and technology trend. Paper presented at the Seminar "Display Technologies" of the Physical Society of Hong Kong

ObservatoryNANO (2011) ICT: Nanotechnology for Flat Panel Displays. Briefing No. 9. 7th Framework Programm Project "ObservatoryNANO", Brussels, Belgium

Plata DL (2009) Carbon nanotube synthesis and detection: limiting the environmental impact of novel technologies. PhD Thesis, Massachusetts Institute of Technology (MIT), Boston, USA 
Rosenbaum R, Bachmann TM, Swirsky Gold L, Huijbregts MAJ, Jolliet O, Juraske R, Koehler A, Larsen HF, MacLeod M, Margni M, McKone T, Payet J, Schuhmacher M, Van de Meent D, Hauschild M (2008) USEtox - the UNEP-SETAC toxicity model: recommended characterisation factors for human toxicity and freshwater ecotoxicity in life cycle impact assessment. Int J Life Cycle Assess 13:532-546

Salieri B (2013) The challenges and the limitations in life cycle impact assessment for metal oxide nanoparticles, a case study on nanoTiO2. Università di Bologna, Bologna, Italy

Salmon R (2012) Displays in the flat panel age and the technologies behind them. A presentation hold on June 10, 2012 at IET Surrey. BBC Research \& Development, London, UK

Steinfeldt M (2007) Assessment of sustainability effects in the context of specific applications. In: Steinfeldt M, Von Gleich A, Petschow U, Haum R (eds) Nanotechnologies, hazards and resource efficiency. Springer, Heidelberg (Germany), p 272

Steinfeldt M, von Gleich A, Petschow U, Haum R, Chudoba T, Haubold S (2004) Nachhaltigkeitseffekte durch Herstellung und Anwendung nanotechnischer Produkte. Institut für ökologische Wirtschaftsforschung $\mathrm{GmbH}$, Berlin, Germany
Thomas V, Caudill R, Badwe D (1988) Marginal emissions and variation across models: Life-cycle assessment of a television. In: IEEE International Symposium on Electronics \& the Environment, Oak Brook, IL, USA, pp 48-53

Upadhyayula VKK, Meyer DE, Curran MA, Gonzalez MA (2012) Screening level cradle to grave life cycle assessment of conceptual 15 inch carbon nanotube (CNT)-field emission display (FED) device. In: NSTI-Nanotech, Santa Clara, CA, USA, NSTI, pp 720 723

Upadhyayula VKK, Meyer DE, Curran MA, Gonzalez MA (2014) Evaluating the environmental impacts of a nano-enhanced field emission display using life cycle assessment: a screening-level study. Environ Sci Technol 48:1194-1205

Verma SS (2010) Flat displays - the future is nano. Electronics for you (October issue): 50-53

Zeng F-G, Zhu C-C, Liu W, Liu X (2006) The fabrication and operation of fully printed carbon nanotube field emission displays. Microelectron J 37:495-499

Zheng K, Shen H, Li J, Sun D, Chen G, Hou K, Li C, Lei W (2009) The fabrication and properties of field emission display based on $\mathrm{ZnO}$ tetrapod-liked nanostructure. Vacuum 83:261-264 